\title{
Editorial: Conflict, Ecological Justice and Rights
}

\author{
WENDY HARCOURT
}

In November 2005, I listened to the silver haired Jane Goodall at an Earth Charter celebration in Amsterdam. ${ }^{1}$ I joined the audience in a standing ovation for her inspiring work through the Roots\&Shoots ${ }^{2}$ programme founded in Tanzania 1991. Emerging from her concern for chimpanzees and the people who lived in the rain forests of Tanzania her global organization engages tens of thousands of young people around the world to show care and concern for human community, animals and the environment.

The pleasant image of global scientific knowledge coming together with compassion and care to support both the lives of gorillas and people threatened by foresters was, however, rudely shattered in my correspondence with Kuntala Lahiri-Dutt one of the authors of this journal issue.

She asked me: 'Often global Non-governmental Organisations (NGOs) talk about things that are not important to local peoples' lives - about illegal logging or illegal mining. If space permitted, I would have written about the 'Save the Gorilla Foundation', which is working in places like Congo where the poor communities are killing each other for coltan or diamond. Who cares for the gorilla when the stomach is empty? I would not care at all, would you?' 3

I thought I did care. Indeed I recalled the time when I visited the local SID Chapter in Ruhenghiri in 1991 and was sent off to visit the mountain gorillas made famous by another animal scientist Dian Fossey of 'Gorillas in the Mist' (Fossey, 1983). I did not relish stomping through wet rain forest with other Europeans led by guides with machetes. Nor did I enjoy being covered in mud and eventually being knocked down by a young male gorilla into the stinging nettles. But I thought it was important to create the nature reserve and appreciated that the proceeds from the film, visits to Fossey's house and the Gorilla Centre created an economically viable form of eco tourism. ${ }^{4}$ One I thought much better than poaching. I was suitably shocked at the illegal selling of hands of gorillas in the local markets. I saw the preservation of the gorilla as a good in its own right, and as a tourist attraction it was helping to feed local people and boost the economy. The question that had always haunted me though, was what happened 3 years later to the women and children walking in the rain under blankets to and from markets in that unbelievably green country side. The point is not that gorillas, or nature - and the work to protect them - are unimportant but the problem, and the potential solutions, cannot be seen independently of the needs and struggles of peoples affected by the same processes. ${ }^{5}$ 
In putting together this journal issue I realised that there were far more connections than I made at the time between the genocide (and the inability of the UN Assistance Mission for Rwanda to contain it) (Dallaire and Beardsley, 2004), ethnic diversity, the legacy of colonial history, the development mission and the struggle of the Rwandan women and children to survive, and their eventual slaughter. As this journal issue shows many of the resource 'conflicts' are in fact the protests of local communities at their displacement and their exclusion from governmental and legal processes that turn over the source of their livelihoods to others. The escalation of such conflict even to the level of genocide is complex but at the root of these resource conflicts are profound economic and social inequalities, and what many, including writers in this journal have termed the violence of development.

This edition of Development therefore aims to present varying views to the dominant approach to natural resource conflict. The dominant thinking is promoted by the World Bank Group together with some of the prominent, mostly northern based environmental NGOs and like minded research institutes. Their approach to environment, natural resource management and sustainable development is one that focuses on nature (gorillas and other animals, Amazon forests and the like) and the struggle to balance the need for economic growth and preserving the environment. The communities that live in the environments are often largely absent in their discussions. The focus is on negotiations with the state, the business elite and foreign corporations, and also possibly with international NGOs representing the affected communities. In the extreme version of this approach conflict happens because of the poor governance skills of the elite, the lack of control of the state and is pushed further by the desperation of the local communities, their ethnic divides, their numbers, their poverty and their lack of knowledge about the global interventions in their terrain. ${ }^{6}$

The articles in this journal present a more nuanced picture. The authors come largely from the South and work or are involved directly in a ers they approach the issue from an anthropological - and often directly political - rather than primarily an economic angle. There is little romanticism here about gorillas and victims of natural resource conflicts. Nor is there any doubt about who benefits from the taking control over the oil wells, gold and diamonds deposits or the land, fisheries, water and forests. It is rarely the communities who live there. The articles explain clearly the political and economic context of the conflicts, and in so doing break down the idea that conflict over natural resources is somehow separate from the larger power games be they the GW Bush war on terror or the global trade regime. They also confront us with the need to question how the concepts of modernity and, in its turn, development have imposed one particular view of nature or environment. This view assumes that natural resources can be plundered for enrichment and growth, emptying other cultural meanings of what it means to live and survive in a particular environment. As the articles in this journal show resources in Malaysia, Romania, Mexico, Sudan, Kenya, Canada, India, South Africa, Iraq, the US and Brazil are far more interwoven with cultural meanings of life. It is because of the clash of these meanings that people are outlawed in their own land. It is in plundering the wealth that comes from these communities' resources that the rich lives of the North and of the elite in the South are built, decidedly at the expense of the dignity, livelihoods and well-being of the majority the world's people.

However, communities are not so ignorant as the powers that are negotiating away their livelihoods seem to think. The strategies for resistance and for adapting to modernity are also evident. In his important introductory article to the journal examining the conflicts over natural resources as a response to neo-liberal globalization, Arturo Escobar ${ }^{7}$ comments:

'The dominant models of development and the economy are making inroads into urban and rural landscapes, the body, and even the molecular fabric of life (for instance, as in the case of transgenic crops and nanotechnology). They introduce environmentally destructive practices that leave landscapes of ecological destruction, some times veritable devasta- 
tion, along the way. It is no wonder that communities world wide are increasingly steadfast, adamant and articulate about the defense of their places, environments and ecosystems.'

There is a complex geopolitics underlying resources, in particular oil. Three of the articles in the issue directly refer to oil, and unabashedly point out the aggressive role of the US in initiating such conflict and war. As Michael Renner states:

'In some places, oil revenues allowed wars to continue ... commercial oil extraction has repeatedly been a source of conflict. All too often, the economic benefits accrue to a small business or government elite while an array of burdens - expropriation of land, disruption of traditional ways of life, environmental devastation, etc. - are imposed on local communities.'

Ricardo Cifuentes Villarroel and Ronnie Hall underscore how globalization and the elites of the corporate world are unashamedly plundering the environment with the connivance of the political elite, including the state and judiciary. Cifuentes in his overview on Latin America puts it bluntly:

'The application of neoliberal policies co-ordinated and imposed through the International Monetary Fund, W[orld] B[ank] and World Trade Organisation, in collusion with the local political networks, creates ... weak environmental regulations, preferential tax regimes, cheap and legally unprotected labour. These conditions allow companies to operate with an [evident] disregard for the affected communities and to use destructive processes, toxic substances and pollutants banned or severely restricted in developed countries. This situation ... now ... is the standard way of doing things.... This is the "only road toward growth" affirm both industry and politicians in unison. Thus, (environmental) disaster has been converted into a system, one of colonial exploitation and alienation, which may be the most perfect in history.'

The articles also expose the complicity of the legal system in these conflicts. When legal systems grant rights of access and use of natural resources to the state and corporations, communities have very little redress. The activities of resistance and survival they then turn to are then defined as illegal, as banditry or anti state, even terrorist, action.
Many of the articles show how local communities have to fight against not only the companies seeking to plunder their land, livelihoods, culture and habitat but also to work against a judicial system that, far from defending their rights, makes laws in order to take community rights away. Gretchen Fox shows in relation to Atlantic Canadian commercial fisheries the struggles of the indigenous peoples to negotiate ecological, economic and cultural sustainability of the fisheries and fishing communities with global interests intent only on profit. The articles on gold mining in Mexico and Romania reveal how laws that the state and global system draw up enrich not the local communities but the foreign companies.

The lack of concern for indigenous communities is evident in Meenakshi Raman's description of the decades of struggles of the Penan Communities to stand up for their rights and defend the last remaining forests that have been brutally logged depriving them of their habitat. Even with the support of the Friends of the Earth Malaysia they have been unable to make the state redress their claims and their living conditions have plummeted in a country "which prides itself in being relatively affluent in the developing world'. In addition, as Patricia Kameri-Mbote and others point out, environmental law has not facilitated women's access to resources and that these legal struggles and the 'development' of natural resources are not gender neutral. Mirian Vilela proposes that an integrated framework for peace and sustainability such as the Earth Charter could be useful to address these interrelated challenges

As in my earlier reference to Rwanda, in areas like Sudan these conflicts are escalating horribly into violence, war and genocide. Munzoul Assal shows how pressure due to structural adjustment programmes and other IMF and World Bank conditionalities has forced the state in Sudan to privatize and open the door for foreign investors in the sectors of agriculture, oil and trade. He argues this has led to a polarizing violence marked by an 'identity consciousness that will likely structure the future of the country'

The sources of conflict over natural resources is not then within the community, or ethnic hatreds, 
or as Kuntala Lahiri-Dutt evocatively suggests a 'complete lack of control and disorder in the third world, whose inhabitants - by some irrational logic of nature - have found themselves endowed with resources that they cannot or do not know how to deal with in an orderly fashion.' She exposes the 'paranoid fear about the unruly third world' and dismisses, as does the journal issue that conflicts over natural resources 'could only be resolved once and for all if either state-owned or multinational corporations take over the control and ownership of mineral resources, and manage them in a systematic manner'. And in the process put profits first and take over the control of what should rightfully belong to the communities.

The solution proposed by the authors is not a simple promotion of communities and indigenous cultures in the face of globalization. Rather it is to promote economic, ecological justice and rights of the communities that will protect and shape their livelihoods and wellbeing. Dana Powell shows how indigenous peoples in North America are able to preserve 'tradition' with the use of high-tech machines. She breaks down the division between nature and culture, modernity and tradition in her discussion about how wind turbines and solar photovoltaic panels have enabled tribes to move beyond fossil fuel extraction as a primary means of economic development, and toward natural resource practices that are more "sustain- able". She concludes: "The wind and the sun introduce new elements of common property to be harnessed for alternative development projects and increased decentralization and ownership over the means of power production.'

To return to Escobar and what promises to be an important and exciting approach to conflict over natural resources that helps us move beyond dominant paradigms. ${ }^{8}$ His political ecology framework asks that we treat economic, ecological and cultural distribution as equally important, and in so doing no longer deny people their rights to their own cultures, ecologies and economies. Such an approach is needed in order to reverse the colonial legacy and to foster people's dignity, well being and livelihoods rather than economic growth fuelled by natural resource depletion and conflict.

As Escobar rightly asserts, 'The fact that a growing number of people and groups demand the right to their own cultures, ecologies and economies as part of our modern social world can no longer be denied. Nor can these demands be easily accommodated into standard liberal or neo-liberal doctrine.' We need to continue to expose the potential violence that underlies the dominant development mission intent on promoting a neo liberal driven economic growth that exploits people, cultures and nature. We need instead to find peaceful and restorative ways of living together that respect all peoples' cultures, community economies, wellbeing and environments.

\section{Notes}

1 Nearly 400 participants from all regions of the world gathered in Amsterdam,The Netherlands, from 7 to 9 November 2005 in order to celebrate the accomplishments of the Earth Charter +5 . See Window on the World for more information on the Earth Charter Initiative and the article in this journal issue by Mirian Vilela.

2 http://www.rootsandshoots.org/

3 E-mail correspondence with Kuntala Lahiri-Dutt (24 May 2006)

4 It cost 100 dollars for the trek to see the gorillas, quite a hefty amount for me, a not so well paid NGO person and a huge amount in local terms.

5 In her response to an earlier draft of the Editorial, Associate Editor Fatma Alloo mentioned two examples in Zanzibar of ecological projects. The first managed to prevent the slaughter of the red Colombus monkeys of Jozaniz forest of Zanzibar, as both governments and communities worked together to make sure the community would directly benefit from eco tourism and thereby agree to stop killing the red monkeys. She contrasted this project with another eco tourist development in Chumbe Island, which has been promoted internationally as a role model of environmental preservation. Here, the lease was given to a German woman who forcibly displaced 100 fishermen who were fishing around the island. It is clear that as the lease holder she is profiting from the tourist trade rather than the fishing community who have instead lost their livelihoods. These examples shows that it is important that integrated conservation and development projects work to the benefit of community rather than are appropriated for private gain. There must always be as Escobar reminds us, questions asked over 'for whose benefit' the project 
is run, and the role of government, conservation experts vs local knowledges and livelihoods. (E-mail Correspondence with Associate Editors, 29 May 2005.)

6 I am not implying all northern based NGOs, but a sizeable majority, I would for example exclude the work of Friends of the Earth that have a better approach. (E-mail Correspondence with Associate Editors, 29 and 30 May 2005).

7 All references that follow are to articles in this issue of Development vol. 49 no. 3.

8 Arturo Escobar elaborates his political ecology framework in forthcoming book due in 2007 on the intersection among development, capital and social movements in the Colombian Pacific region in the context of the transnational debates on rainforest political ecology and biodiversity conservation.

\section{References}

Dallaire, Romeo and Major Brent Beardsley (2004) Shake Hands with the Devil: The Failure of Humanity in Rwanda, Canada:TorontoVintage.

Fossey, Dian (1983) Gorillas in the Mist, NY: Houghton, Mifflin \& Company/Marina Books. 